EGG-11265-1125

$\mathrm{UC}-708$

\title{
LESSONS LEARNED FROM FRMAC-93 EXERCISE
}

Kenneth C. Kerns

EG\&G Energy Measurements

P.O. Box 1912, MS RSL-24

Las Vegas, NV 89125

(702) $295-8777$

\section{SUMMARY}

FRMAC-93 was a full field exercise conducted to test the ability of the Federal Radiological Monitoring and Assessment Center (FRMAC) to support the State(s) and Lead Federal Agency (LFA) in a response to a major radiological accident. One of the key objectives was to test the relationship between the FRMAC and the States of Nebraska and Iowa, and the Nuclear Regulatory Commission (NRC). Because this was a no fault exercise, this was seen as an opportunity to train new personnel. As a result of the exercise many lessons were documented which resulted in changes to FRMAC policies and procedures. These changes allowed the FRMAC to develop closer relationships with the State(s) and LFAs.

\section{INTRODUCTION}

FRMAC-93 simulated a radiological accident at the Ft. Calhoun Nuclear Power Plant, 25 miles north of Omaha, Nebraska. The exercise involved the states of Iowa and Nebraska, the NRC as the LFA, the FRMAC, and several Federal Agencies with statutory responsibility for providing extensive assistance during any national emergency.

The U.S. Department of Energy (DOE) has technical expertise in areas of radiation assistance, assessments, and capabilities for the Federal Government. Because of this expertise, the Federal Radiological Emergency Response Plan (FRERP) has given DOE the responsibility for managing the FRMAC during an emergency response. In the event of a major radiological emergency, DOE/Nevada provides emergency response assistance and support to the States and LFA through the FRMAC. This assistance is designed to augment existing State resources in a coordinated effort to mitigate the consequences of a significant radiological accident.

\section{EXERCISE DESIGN}

FRMAC-93 was a major two-day field exercise designed to determine the effectiveness, coordination, and operations of a DOE-managed FRMAC. Two important objectives of the exercise were to ensure that appropriate priorities were established and assistance was provided to the States and LFA by the FRMAC. Although some unanticipated difficulties were encountered in the initial phases of operation, the exercise objectives were fully met by the time the exercise concluded on Day 3.

Day 1 involved the Fort Calhoun Power Station evaluated plume phase exercise. After that exercise, meetings between the DOE Radiological Assistance Program (RAP) Team, the FRMAC Advance Party, and the States signaled the beginning of FRMAC-93.

Day 2 of the exercise involved the initial setup of the FRMAC. Twenty field teams, consisting of the U.S. Environmental Protection Agency (EPA), DOE, NRC, and State field monitors were dispatched to the areas surrounding Fort Calhoun to begin characterizing the radiological impact of the accident. These teams took environmental radiation measurements and collected air, soil, water, milk, and agricultural samples to be analyzed by three mobile laboratories supporting the exercise. The information collected in the field was quality checked and given to the FRMAC Evaluation and Assessment Division to provide dose assessments to the States and LFA.

A weakness was identified in the FRMAC's ability to support state radiological decision makers. Raw data were not provided to the States in a timely 


\section{DISCLAIMER}

Portions of this document may be illegible in electronic image products. Images are produced from the best available original document. 
manner because of the FRMAC policy to ensure the highest quality data. That policy was changed during the exercise to allow raw data to be given directly to the States to allow their health physicists to conduct simultaneous dose assessments. The States also had difficulty addressing their priorities due to procedures which did not allow the State representatives to interface directly with the FRMAC Director. By the end of the second day these problems, as well as a host of others, were addressed and corrected in a meeting with the FRMAC Director, State representatives, and the Lead Exercise Controllers.

Day 3, the final day of the exercise, saw a better understanding of the needs and priorities of the States and LFA by FRMAC staff and a better appreciation by the States of the resources that can be provided by the FRMAC. The FRMAC management ensured that all major decisions involved the States and LFA. FRMAC management viewed key State radiological decision makers as an integral part of the team effort.

From the onset, FRMAC-93 was considered by all as a "no-fault" exercise. It was not to be a demonstration of agency capabilities much like the Federal Field Exercises. Participants were tasked to play the exercise as they would expect to respond in an actual event. To create an environment which would resemble an actual no-notice response, the participants in FRMAC-93 were not given prior training in the current FRMAC policies and procedures and were expected to respond using existing knowledge and procedures available. Players were given briefings which outlined the rules of the exercise and real time safety concerns. However, after the players were given their assignments, they were encouraged to operate as if the response were real, with minimal controller input. This allowed a realistic assessment of the effectiveness of the FRMAC Training and Outreach Program.

Exercises of the magnitude of FRMAC-93 are indeed rare. The exercise enabled planners and program managers to test new procedures and documentation, train new players, and allow the players to respond to technical situations in the manner they would expect in an actual emergency response. The intent of all exercises, including FRMAC-93, is to provide players and the opportunity to learn from errors, and apply those errors in improving FRMAC operations should the need arise during an actual deployment. State, LFA, and FRMAC managers are acutely aware of the mistakes made at FRMAC-93. Their experiences will provide them with the necessary tools should an actual deployment occur.

\section{LESSONS LEARNED}

Some of the major deficiencies noted during the FRMAC-93 Exercise and the corrective actions taken are discussed below: ${ }^{1}$

\section{A. Issue 1.}

Because the State(s) are responsible for protective actions, it is imperative that the FRMAC management and other Federal agency representatives initiate early contact with their State counterparts to establish the proper working relationships. This relationship was not in effect early in FRMAC-93. As a result of this finding, FRMAC Advance Party procedures and checklists were developed as a guide during the initial meeting with State representatives.

A DOE State outreach program is under development in coordination with the NRC and Federal Emergency Management Agency (FEMA) outreach programs to include greater emphasis on FRMAC structure, policies, and procedures.

\section{B. Issue 2.}

An initial monitoring and sampling plan was developed with input from a State representative before the field monitoring teams were dispatched from the FRMAC. However, the major decision makers for the States were not involved in this planning. The new FRMAC policy dictates that the plan is developed at the initial advance party meeting with the State decision makers to elevate the importance of the plan and to ensure a full cooperative effort. In addition to the State representatives, the Evaluation and Assessment Manager and the Senior Scientific Advisor consult in developing the monitoring plan. A generic monitoring and sampling plan may be used to direct field monitoring and sampling activities until well-defined goals and priorities are developed with the State, LFA, and FRMAC.

\section{Issue 3.}

The FRMAC Director and his key staff were often not available to meet with the State and LFA representatives. When the Director called meetings with the FRMAC division managers, the group 
operations became greatly impaired and no decision makers were left on the FRMAC floor to address the concerns and questions of the States.

FRMAC procedures have been modified to create a deputy position for each division; the deputies will have detailed knowledge of general FRMAC operations and will assume responsibility for the continuation of operations. Additionally, in each Division State representatives will work directly with the manager to provide the local expertise needed for an effective environmental monitoring and assessment effort.

State and LFA representatives are now collocated with the FRMAC director and are included in all decision making processes. This will ensure that the needs and priorities of the State(s) are addressed at the highest level in the FRMAC.

\section{Issue 4.}

FRMAC field and laboratory raw data were not immediately distributed to the States and LFA. Early field monitoring results may be all that the State(s) have on which to base protective actions. The FRMAC policy was to ensure that the data provided to the States were of the highest quality and would be defensible. The quest for quality greatly slowed down the distribution of data. Recognizing the need for a balance between quality data and rapid data distribution, the policy for field and laboratory data distribution within the FRMAC has been changed to allow an immediate wide distribution within the FRMAC, especially to the State and LFA representatives. Only cursory quality checks are applied before distribution. The raw data should be used carefully until the integrity of the data can be validated. Official FRMAC products will still go through the quality assurance and approval process before being released formally to the State(s) and LFA.

\section{E. Issue 5.}

Training must become a routine part of any emergency response system. The lack of familiarization with procedures and equipment in the FRMAC was apparent at all levels. A large-scale exercise every few years is not sufficient to ensure that adequately trained personnel will be available for a real event. The FRMAC approach to training has been modified to center around smaller, more focused drills. This will ensure that each level of the
FRMAC is adequately exercised. These drills will be designed specifically for each functional element of the FRMAC. HANDSHAKE ONE was a field drill held at the Nevada Test Site in July 1994 to test the field dispatch, field operations, and radio communications. The Evaluation and Assessment Division exercised concurrently with the field monitors. This level of drill is not only cost effective but also provides a very good training platform. To test the effectiveness of the FRMAC training and drills, FRMAC plans to participate in one largescale, full field exercise every three years.

\section{F. Issue 6.}

FRMAC personnel were not given periodic briefings. Although information was given to the key managers during meetings, the information was not always passed along. Field teams did not receive updates on weather or radiological conditions. New procedures call for brief $(10-15 \mathrm{~min}$.) all-hands meetings to be held periodically to give updates on the status of the plant conditions, goals and priorities for the FRMAC, status of the response, health and safety considerations, and any other important information.

\section{G. Issue 7 .}

The FRMAC placed too much reliance on computer technology for data retrieval and display. Dependence on the automated systems impaired the FRMAC's ability to complete assessments when the systems malfunctioned (the system malfunctions were part of the exercise design and were initiated by controllers). Procedures have been modified which will allow the primary route of data analysis to shift from computer technology to manual calculations and plotting when technological problems occur. This bypass system for critical data will ensure that data are assessed without delay.

\section{H. Issue 8.}

The request tracking system and the data/information flow did not work efficiently. Too many steps, checks, and balances in the FRMAC procedures contributed to the FRMAC being ineffective on Day 2. The request tracking system is a necessary part of the FRMAC and the new tracking system has been simplified. The data/information flow was revised to remove bottlenecks which may cause delays within the FRMAC. Priority 
information is identified and distributed without delay.

\section{Issue 9.}

This exercise was used as a training platform for some new FRMAC managers who received coaching during the exercise from more experienced managers. This proved to be a very ineffective training tool. Most of the coaches were not sure how much assistance they should give to the exercise participants and often did not provide guidance when it was needed the most. A full field exercise should never be used as a training evolution. Too much effort put into planning an exercise of this scale to not have the most qualified personnel participating. Training new personnel can be achieved in drills.

\section{J. Issue 10.}

FRMAC 93 was not intended to exercise the start up process of a response, but that is what occurred for the first half day of the exercise. Many of players had never worked together and it took half a day to discover the roles, responsibilities and capabilities of each of the players. This feeling-out process combined with players who were not familiar with their roles contributed to the poor start of the exercise. If the exercise objectives do not include testing the start up process, a walk-through should be conducted for each area and position prior to the exercise.

\section{CONCLUSION}

As a result of the lessons learned during FRMAC 93, the FRMAC program managers and staff have suggested and implemented changes to the FRMAC organization, procedures, and policies. The FRMAC participated in another exercise held in September 1993 at the DOE Hanford Site in Washington, which allowed the effectiveness of these changes to be tested. The results of the Hanford exercise were very positive: the States became part of the FRMAC and were treated more as partners than customers.
This work was performed for the Department of Energy under contract No. DE-AC08-93NV11265.

By acceptance of this article, the publisher and/or recipient acknowledges the U.S. Government's right to retain a nonexclusive, royalty free license in and to any copyright covering the article.

\section{REFERENCES}

1. K. C. Kerns, "FRMAC-93 Lessons Learned Report", DOE/NV-367 UC-700 (1994) 